\title{
Evaluation of Mobile Supervision Application and Electronic Medicine Box for Tuberculosis Patients: Implementation Experience from Tianjin During 2019-2020
}

\author{
Xiaorong Li \\ Tianjin Center for Tuberculosis Control \\ Xuewen pang \\ Tianjin center for tuberculosis control \\ Fan Zhang ( $\sim 13312119095 @ 126 . c o m$ ) \\ Tianjin Center for Tuberculosis Control
}

\section{Research article}

Keywords: Tuberculosis, electronic medicine box, APP, medication adherence

Posted Date: January 14th, 2021

DOI: https://doi.org/10.21203/rs.3.rs-143692/v1

License: (c) (i) This work is licensed under a Creative Commons Attribution 4.0 International License.

Read Full License 


\section{Abstract}

Backgroud Poor tuberculosis (TB) medication adherence increases the risk of treatment failure and development of drug-resistant TB, while universal implementation of directly observed therapy (DOT) is not feasible in China. EHealth technologies were reported to be promising patient-centered tools for improving adherence. However, only pilot studies have assessed patients' experiences and the results were discrepant.

Methods This cross sectional study study was conducted among TB patients at the outpatient department from 3 March 2019 to 30 May 2020 in Tianjin, China. Data were downloaded from the Tuberculosis doctor App and TB Information Management System (TBIMS), and merged them using the TBIMS notification number. Logistic regression analysis was used to analyze the factors associated with regualar drug-intake. Odds ratios and 95\% confident intervals were estimated with and without adjustment for age, gender, ethnicity and occupation. Results A total of 1193 TB patients were recruited, of whom $33.28 \%$ (397) patients were regular drug-intake. The whole drug-intake rate was $84.84 \%$, except for the first month, the drug-intake rate decreased with the increase of monthly treatment sequence. After adjustment by age, gender, ethnicity and occupation, tuberculosis pleurisy (aOR: $0.42,95 \mathrm{Cl} \%=0.26-0.69$ ) and retreated patients (aOR: $0.40,95 \mathrm{Cl} \%=0.27-0.59)$ were more likely to have poor medication compliance. Local resident tend to have better medication compliance (aOR: $1.80,95 \mathrm{Cl} \%=1.16-2.79$ ).

Conclusions The medication adherence at the first month should be noticed. Medication adherence was poor in tuberculosis pleuritis and retreated patients, while local resident tend to have better medication adherence. To make full use of the application of eHealth in TB patient management, more incentive measures should be adopted for patients and doctors respectively.

\section{Full Text}

Due to technical limitations, full-text HTML conversion of this manuscript could not be completed. However, the latest manuscript can be downloaded and accessed as a PDF.

\section{Figures}




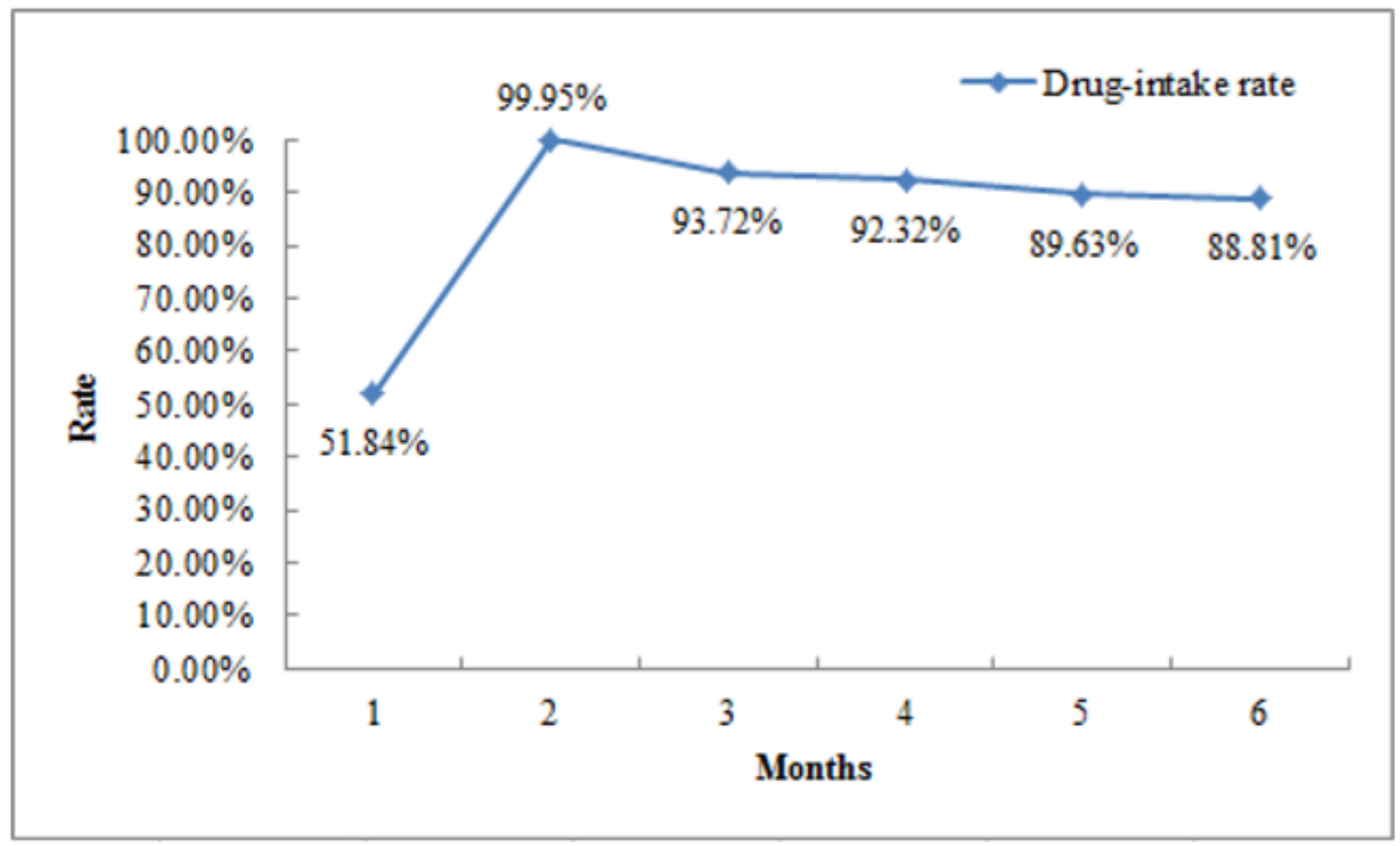

Figure 1

Drug-intake rate in different month 